\title{
Sensory and Biochemical Characterization of Novel Drinks Based on Tomato Juice
}

\author{
Fabio Alfieri ${ }^{1^{*}}$, Alessandro Genovese ${ }^{1}{ }^{(}$, Antonello Paduano $^{2}{ }^{\circledR}$, Eva Campo $^{3}$, Rosa Oria $^{3}$, Pasquale \\ Ferranti $^{*{ }^{*}(\mathbb{C}}$
}

\author{
${ }^{1}$ Department of Agricultural Sciences, Division of Food Science and Technology, University of Naples Federico II, Via Università \\ 100,80055 , Portici, NA, Italy \\ ${ }^{2}$ Department of Agricultural and Environmental Sciences, University of Bari Aldo Moro, Via Orabona 4, 70125, Bari, Italy \\ ${ }^{3}$ Plant Food Research Group, Aragon Agrifood Institute-IA2 (University of Zaragoza-CITA), C/Miguel Servet 177, 50013, Zaragoza, \\ Spain \\ Email: fabio.alfieri@unina.it, ferranti@unina.it
}

Received: 16 September 2020; Revised: 5 December 2020; Accepted: 10 December 2020

\begin{abstract}
In these last years, consumers' choices are being directed towards healthier food and beverages with an increasing demand for functional products. In this study, we investigated the sensory and biochemical properties of novel drinks based on tomato juice. To this purpose, different blends were formulated mixing fresh tomato juice with other fruit juices and nectars in different proportions and then assayed to investigate their sensory (panel test), compositional and biochemical characteristics. Our results indicated that it is possible to formulate tasty drinks based on tomato juice with improved nutritional properties. The combinations of red fruits/tomato $(60 / 40 \mathrm{v} / \mathrm{v})$ and red fruits/ orange/tomato $(40 / 30 / 30 \mathrm{v} / \mathrm{v} / \mathrm{v})$ showed a sugar content lower than those of different soft drinks on the market including energy drinks, and suitable lycopene levels as well. Interestingly, the blended red fruits/orange/tomato had a greater number of polyphenols and vitamin $\mathrm{C}$, a softer tomato flavour and high sensory appreciation. High pasteurization $\left(90^{\circ} \mathrm{C}\right.$, $7 \mathrm{~min}$ ), performed to increase storability, did not significantly affect sensory and biochemical properties of drinks. These achievements may be useful to modulate tomato flavour release and consumer acceptability of novel drinks based on tomato juice.
\end{abstract}

Keywords: functional beverage, soft drink, lycopene, polyphenols, tomato flavour, high pasteurization

\section{Introduction}

The global tomato processing market is aided by the rising production as well as consumption of processed tomatoes. 42 million tonnes of processed tomatoes were consumed globally in 2019, with an expected consumption of 51 million tonnes in 2025 [1]. However, the global tomato juice market is limited in comparison to that of other tomatobased products, i.e. peeled, chopped, puree and tomato paste, which are leading products on international trade [1-2]. In addition, tomato juice consumption is very limited in comparison to that of other soft drinks with lower nutritional properties such as energy drinks, which are very popular among young consumers despite their low nutritional value [34].

The high interest in energy drinks is mainly linked to their likable taste, stimulating effect and purpose to boost physical performance. In fact, these soft drinks are formulated with the aim to provide the consumers with a "plus" Copyright (C2021 Fabio Alfieri, et al.

DOI: https://doi.org/10.37256/fse.212021645

This is an open-access article distributed under a CC BY license

(Creative Commons Attribution 4.0 International License)

https://creativecommons.org/licenses/by/4.0/ 
of energy through a combination of stimulants and sugars (e.g. caffeine, herbal extracts, B vitamins, amino acids and sugar derivatives) [5-6]. Caffeine and sugars can reach concentrations of $35 \mathrm{mg}$ and $15.6 \mathrm{~g}$ per $100 \mathrm{~mL}$ of energy drink, respectively [7]. Chronic caffeine consumption may provoke health concerns related to central nervous system, cardiovascular, gastrointestinal and renal dysfunction [5-6, 8]. Sugar levels in energy drinks are comparable to those of other common sugar-based beverages associated with increasing body weight and obesity in young people (including children) and adults [7]. The absence of caffeine as well as the wide range of minerals and adequate sugar amounts contained in tomato and other fruits make their juices an optimal source for drinks aiming to support physical performance and promote energy recovery as much as energy drinks. Moreover, tomato is one of the major sources of lycopene and a good source of vitamin $\mathrm{C}$ and several antioxidant molecules which may provide tomato juice with functional properties [9-10]. Lycopene and vitamin C, in presence of other micronutrients, may have a synergistic effect on preventing certain type of cancer (lung, stomach, prostate, breast, pancreas, etc.) [9-10].

If we focus on commercial data, there was an increase in soft drink demand with a world market share of $3.2 \%$ in 2013 against that of $2.9 \%$ in 2008 with potential growth of 216.74 billion dollars during 2020-2024 [3-4]. Interestingly, consumers are increasingly demanding for functional products with positive effects on health among which there are also examples of soft drinks based on tomato juice such as fermented or aromatic beverages [10-12]; a trend confirmed by Zhu et al. [13] in their study on consumer preference and willingness to pay for tomato juice. The study results showed that tomato juices with fresh aroma notes and better taste will encourage consumers' purchase intent.

Thereby, the present research aimed to investigate the sensory and functional properties of some novel drinks based on fruit juices, including tomato juice, as potential new proposals on soft drinks market. Since in literature similar studies, including that performed on Physalis (Physalis peruviana L.) juice by Rabie et al. [14], have suggested that pasteurization may preserve the valuable attributes of juices (e.g. ascorbic acid and total phenolic), we decided comparing the sensory and biochemical data obtained for raw and pasteurized blends. In addition, both caloric intake and sugar content of the novel drinks were compared to those of some energy drinks on the market.

\section{Materials and methods}

\subsection{Materials}

Tomato juice used for drink production was made from fresh tomato fruits of the round cluster variety (deep red colour tomatoes with strong green parts and sweet taste. Normally used for salads and juices). Fruit juices and nectars were the following commercial products: a) 100\% orange (Skipper Zuegg, local market) and b) red fruits (strawberry, red grapes, black cherry, red currant, cranberry; Skipper Zuegg, local market).

Gallic acid standard, Folin-Ciocalteu and 2,4,6-Tri(2-pyridyl)-s-triazine (TPTZ) reagents were purchased from Sigma (St Louis, MO, USA), ascorbic acid standard, dichlorophenolindophenol, metaphosphoric and acetic acids were purchased from Panreac (Barcelona, Spain). Fehling A and Fehling B reagents were purchased from J.T. Baker Chemicals (Deventer, Holland). Carrez I and Carrez II, water, acetone, methanol, hexane, 2,2'-azinobis-(3-ethylbenzthiazoline-6-sulfonic) diammonium salt (ABTS), Tetrahydrofuran (THF), butylatedhydroxytoluene (BHT), methylene

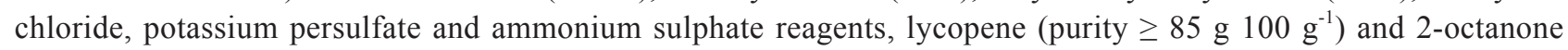
standards were purchased from Sigma-Aldrich (Steinheim, Germany).

\subsection{Preparation and formulation of drinks}

Tomato fruits were washed, cut in small pieces and chopped using a mixer. The fresh juice was roughly filtered through a $0.32 \mathrm{~mm}$ fine mesh steel strainer (Paderno, Novara, Italy) to remove peels and seeds and then blanched $\left(65^{\circ} \mathrm{C}, 5 \mathrm{~min}\right)$ to produce a softer texture (pectinase activation). Hence, tomato juice was mixed with commercial fruit juices and nectars in the following proportions: red fruits/orange/tomato $(40 / 30 / 30 \mathrm{v} / \mathrm{v} / \mathrm{v} ; 30 / 40 / 30 \mathrm{v} / \mathrm{v} / \mathrm{v} ; 30 / 30 / 40 \mathrm{v} /$ $\mathrm{v} / \mathrm{v})$, orange/tomato and red fruits/tomato $(20 / 80 \mathrm{v} / \mathrm{v} ; 40 / 60 \mathrm{v} / \mathrm{v} ; 50 / 50 \mathrm{v} / \mathrm{v} ; 60 / 40 \mathrm{v} / \mathrm{v} ; 80 / 20 \mathrm{v} / \mathrm{v})$. Among them, two combinations were selected through a preliminary sensory test: red fruits/tomato $(60 / 40 \mathrm{v} / \mathrm{v})(\mathrm{S} 1)$ and red fruits/orange/ tomato $(40 / 30 / 30 \mathrm{v} / \mathrm{v} / \mathrm{v})(\mathrm{S} 2)$. The other combinations were rejected because of their low global appreciation $(<4)$ and high tomato flavour $(>7)$. Aliquots of these blends were also subjected to high pasteurization by autoclaving $\left(90^{\circ} \mathrm{C}, 7\right.$ $\mathrm{min}$ ) with the purpose to assess how pasteurization process may affect the sensory and biochemical properties of drinks. 


\subsection{Panel test}

Panel test was carried out to adopt different protocols by a panel of 10 judges ( 5 men and 5 women) recruited among students, researchers and professors from the University of Zaragoza, Faculty of Veterinary [15-17]. The panel evaluated the following attributes: global intensity (flavour perception), tomato flavour, red berry fruit flavour, orange flavour, sweet taste, sour taste, bitter taste and global appreciation. The intensity of each attribute and the global appreciation of the tested blends were indicated on a 10 points scale (attribute intensity: $0=10$ intensity, $10=$ high intensity; global appreciation: $0=$ not appreciated, $10=$ very appreciated). Raw and pasteurized samples were prepared $1 \mathrm{~h}$ before the evaluation and coded with random numbers. They were served at $4{ }^{\circ} \mathrm{C}$ temperature in random order. The panel was provided with unsalted crackers and water to clear palate between sample tasting.

\subsection{Sample preparation for biochemical analyses}

The aqueous and organic extracts of drinks were obtained according to the method reported by Djuric and Powell [18] with slight changes. $1 \mathrm{~mL}$ of each blend was mixed with $0.5 \mathrm{~mL}$ of water and centrifuged $(4000 \mathrm{~g} \times 5 \mathrm{~min})$. The pellets were washed with $0.5 \mathrm{~mL}$ of water twice and the supernatants were combined to yield the aqueous fraction (AF). The pellets were then washed four times with $1 \mathrm{~mL}$ of acetone/methanol $(7 / 3, \mathrm{v} / \mathrm{v})$, using vigorous vortexing and sonication. After centrifugation, the supernatants were combined to yield the organic fraction (OF).

For total polyphenol compound and vitamin $\mathrm{C}$ analysis, $10 \mathrm{~mL}$ of each sample were subjected to homogenization and 1/10 dilution with water. After stirring, the samples were assayed directly without centrifugation.

For sugar determination, since sugar solutions must have a sugar concentration between 0.5 and $1 \mathrm{~g} 100 \mathrm{~mL}^{-1}, 5 \mathrm{~mL}$ of each sample were diluted 20 times with water. Then, the samples were subjected to defecation in order to eliminate interfering substances (i.e. tannins and pectins) by using Carrez reagents.

\subsection{Total polyphenol compounds}

The analysis of total polyphenol compounds was performed according to Singleton and Rossi [19] using the FolinCiocalteau colorimetric method. The total phenolic content was determined by using a calibration curve performed with gallic acid and expressed as mg of gallic acid per L of solution. The analyses were carried out in triplicate for each sample.

\subsection{Lycopene content}

In order to extract lycopene from drink OFs, $4 \mathrm{~mL}$ of each fraction were mixed with $10 \mathrm{~mL}$ of hexane. The solutions were stirred and thus left to stand for $15 \mathrm{~min}$. Hence, $2 \mathrm{~mL}$ of the hexane phases containing lycopene were dried under nitrogen and then mixed with $1 \mathrm{~mL}$ of THF. The lycopene content was determined by High Performance Liquid Chromatography (HPLC) analysis following the procedure of De Sio et al. [20] with appropriate changes. The analysis was performed on an Agilent 1100 Series coupled with a Diode array UV-Vis detector. Data were collected at $472 \mathrm{~nm}$. The column was a reverse-phase Phenomenex Ultracarb ODS30 $(7 \mu \mathrm{m}, 250 \mathrm{~mm} \times 4.6 \mathrm{~mm})$. The injection volume was $50 \mu \mathrm{L}$. The elution was performed with a linear gradient of methanol/water $95 / 5(\mathrm{v} / \mathrm{v})$ containing BHT 0.1 g $100 \mathrm{~mL}^{-1}$ (eluent A) and methylene chloride containing BHT $0.1 \mathrm{~g} 100 \mathrm{~mL}^{-1}$ (eleunt B). The flow rate was $1.0 \mathrm{~mL}$ $\mathrm{min}^{-1}$. The gradient, starting at sample injection, was from $5 \% \mathrm{~B}$ in A to $70 \% \mathrm{~B}$ in A in 35 min. A calibration curve was prepared using different concentrations of lycopene standard. The analysis was made in triplicate and the results were expressed in $\mathrm{mg}$ of lycopene per $\mathrm{L}$ of solution.

\subsection{Antioxidant activity}

The antioxidant activity was measured by ABTS analysis according to the method reported by Re et al. [21]. Briefly, ABTS reactive was dissolved in $5 \mathrm{~mL}$ of water to obtain a concentration of $7 \mathrm{mmol} \mathrm{L}^{-3}$. Then, $88 \mu \mathrm{L}$ of 2.45 mmol L $\mathrm{L}^{-3}$ potassium persulfate solution was added to form the radical cation $\mathrm{ABTS}^{+}$. The mixture was stored in the dark at $4-6^{\circ} \mathrm{C}$ for $12-16 \mathrm{~h}$ before use. The $\mathrm{ABTS}^{+}$stock solution was diluted with ethanol to reach an absorbance of $0.70 \pm$ 0.02 at $734 \mathrm{~nm}\left(25^{\circ} \mathrm{C}\right)$. A calibration curve was prepared in diluting Trolox in ethanol by using concentrations from 4.5 
to $30 \mu \mathrm{g} \mathrm{mL}^{-1}$. The analysis was carried out after exactly 2.5 minutes of sample addition and the absorbance was read at $734 \mathrm{~nm}$ by using a spectrophotometer mod. UV-1601 (Shimadzu Italia, Milan, Italy). For each dilution, the percentage of inhibition was calculated using the formula $A_{734} \%=\left(1-A_{f} / A_{0}\right) * 100$, where $A_{0}$ was the absorbance of blank sample and $\mathrm{A}_{\mathrm{f}}$ was the absorbance after $2.5 \mathrm{~min}$. The inhibition percentage was plotted as a function of Trolox concentrations. The antioxidant activity of the samples was calculated from the ratio of linear regression coefficient of the analyte and that of the Trolox. The analysis was made in triplicate and the results were expressed in mg of Trolox equivalent per Liter of solution. The free radical scavenging ability of the drink extracts and Trolox against ABTS ${ }^{+}$free radical was evaluated mixing $100 \mu \mathrm{L}$ of extracts with $1000 \mu \mathrm{L}$ of $\mathrm{ABTS}^{+}$methanolic solution. After 2.5 minutes of incubation at room temperature in the dark, the absorbance was measured at $734 \mathrm{~nm}$.

\subsection{Vitamin C content}

The vitamin $\mathrm{C}$ content was determined by the titration method of Lees [22]. To carry out the analysis, the following reagents were used: a dichlorophenolindophenol solution $\left(50 \mathrm{mg} 100 \mathrm{~mL}^{-1}\right)$; an ascorbic acid stock solution (5 mg 500 $\mathrm{mL}^{-1}$ ); a solution containing $15 \mathrm{~g}$ of metaphosphoric acid in $40 \mathrm{~mL}$ of acetic acid; and $450 \mathrm{~mL}$ of water. A calibration curve was prepared using different concentrations of ascorbic acid. The titration proceeded with an indophenol solution until a pale pink coloration persistent for at least 5 seconds. Then, the milliliters of solution used in the titration were pinned. The vitamin $\mathrm{C}$ content was calculated by the amount of $\mathrm{mg}$ of ascorbic acid on $100 \mathrm{~mL}$ of sample using a calibration curve. The analysis was made in triplicate and the results were expressed in $\mathrm{mg}$ of ascorbic acid per L of solution.

\subsection{Sugar content}

The sugar content was measured by Fehling method. The titration was made in triplicate and the results were expressed both in $\mathrm{kcal} \mathrm{L}^{-1}$ and $\mathrm{g} \mathrm{L}^{-1}$.

\subsection{Volatile compounds}

The volatile compound composition was determined by dynamic headspace-solid phase microextraction (SPME)GC/MS analysis using the method reported by Lisanti et al. [23] modified as follows. $25 \mathrm{~mL}$ of each blend was placed in a $50 \mathrm{~mL}$ glass bottle together with $25 \mathrm{~mL}$ of a saturated solution of ammonium sulphate in order to avoid changes of volatile components due to the action of endogenous tomato enzymes. Then, $50 \mu \mathrm{L}$ of a water solution of 2-octanone (5.2 $\left.\mathrm{mg} \mathrm{L}^{-1}\right)$ (internal standard) were added. Afterwards, the samples were subjected to magnetic stirring $\left(30^{\circ} \mathrm{C}, 15 \mathrm{~min}\right)$ in order to facilitate the extraction of volatile components. The SPME fiber was inserted through the cap septum into the headspace of samples for $30 \mathrm{~min}$ at $30^{\circ} \mathrm{C}$. The SPME device (Supelco Co., Bellefonte, PA, USA) was equipped with an $85 \mu \mathrm{m}$ carboxen/polydimethylsiloxane (CAR/PDMS) fiber coated with a $1 \mathrm{~cm}$ length stationary phase. Volatile compound thermal desorption was carried out by exposing the SPME fiber in the injector for 10 min. The fiber was previously conditioned at $300^{\circ} \mathrm{C}$ for $2 \mathrm{~h}$. Before each analysis, a blank test was performed to prevent the release of undesirable compounds. Volatile compounds were analysed by using a GC Agilent Technologies model GC 6890N (Santa Clara, CA, USA) coupled with a mass spectrometer MS 5973N equipped with HP-5MS capillary column (30 m $\times 0.25 \mathrm{~mm}$ i.d.; with $0.25 \mu \mathrm{m}$ film thickness) (JandW Scientific, Folsom, CA, USA). The temperature was set at $40^{\circ} \mathrm{C}$ for $5 \mathrm{~min}$ followed by an increase of $3^{\circ} \mathrm{C} \mathrm{min}^{-1}$ up to $140^{\circ} \mathrm{C}$ and, then, increased to $300^{\circ} \mathrm{C}$ at $30^{\circ} \mathrm{C} \mathrm{min}{ }^{-1}$ for $1 \mathrm{~min}^{\circ}$ The injector was kept at $300^{\circ} \mathrm{C}$. Helium was used as carrier gas $\left(1.0 \mathrm{~mL} \mathrm{~min}^{-1}\right)$ [24]. Compound identification was performed by comparing retention times and mass spectra obtained by analysing pure reference compounds under the same conditions. Moreover, the identification was confirmed by comparing the mass spectra with those of the NIST database. In a few cases, the pure chemical standard was not available, thus the compounds were labelled as tentative ( $\mathrm{t}$ ). Mass spectra were recorded at $70 \mathrm{eV}$. The peak area of each compound was normalized with respect to the area of the internal standard peak. Each sample was analysed in triplicate. 


\subsection{Statistical treatment of data}

Significant quantitative differences among the samples were determined for each compound by performing a oneway analysis of variance (ANOVA). Tukey's test was used to discriminate among the mean values of the variables. Differences were considered significant at $\mathrm{p}<0.05$. Data elaboration was carried out using XL Stat (version 2009.3.02), an add-in software package for Microsoft Excel (Addinsoft Corp., Paris, France).

PLS analysis was performed on lycopene, total polyphenols $\left(\mathrm{mg} \mathrm{L}^{-1}\right)$, antioxidant activity $\left(\mathrm{mg} \mathrm{L}^{-1}\right)$, vitamin $\mathrm{C}(\mathrm{mg}$ $\left.\mathrm{L}^{-1}\right)$, sugars $\left(\mathrm{g} \mathrm{L}^{-1}\right)$, volatile compounds $\left(\mu \mathrm{g} \mathrm{L}^{-1}\right)$ and sensory data to observe the main differences among the proposed drinks.

\section{Results and discussion}

Sensory profiles of S1 and S2 are reported in Table 1. After heat treatment, the sensory attributes of pasteurized samples (PS1 and PS2) did not change significantly compared to those of raw samples (RS1 and RS2). However, PS2 was associated with higher bitter taste, lower sweet taste and lower global appreciation. These changes were probably due to chemical reactions of sugars triggered by the high temperature (i.e. Mallard's reaction) [25]. As expected, S2 showed a tomato flavour significantly lower than that of S1, either before or after pasteurization. The small perception of this attribute in $\mathrm{S} 2$ was associated mainly to its lower amount of tomato juice (only $30 \mathrm{~mL} 100 \mathrm{~mL}^{-1}$ ). Again, the absence of orange juice in S1 explains its smaller orange flavour and sour taste compared to S2. Although global appreciation of RS2 was higher than that of RS1, this difference was not significant after the thermal treatment.

Table 1. Average values of sensory attributes of raw (RS1, RS2) and pasteurized (PS1, PS2) blends

\begin{tabular}{ccccc}
\hline \multirow{2}{*}{ Attributes } & \multicolumn{3}{c}{ Samples } \\
\cline { 2 - 4 } & RS1 & PS1 & RS2 & PS2 \\
\hline Global intensity & $7.1 \mathrm{a}$ & $6.1 \mathrm{a}$ & $6.4 \mathrm{a}$ & $6.8 \mathrm{a}$ \\
Tomato flavour & $6.5 \mathrm{a}^{*}$ & $5.4 \mathrm{a}$ & $4.3 \mathrm{a}$ & $4.7 \mathrm{a}$ \\
Red berry fruit flavour & $5.3 \mathrm{a}$ & $5.9 \mathrm{a}$ & $5.4 \mathrm{a}$ & $5.7 \mathrm{a}$ \\
Orange flavour & $0.6 \mathrm{a}$ & $1.5 \mathrm{a}$ & $4.6 \mathrm{a}^{*}$ & $5.5 \mathrm{a}^{*}$ \\
Sweet taste & $6.3 \mathrm{a}$ & $6.7 \mathrm{a}$ & $6.5 \mathrm{a}$ & $5.4 \mathrm{a}$ \\
Sour taste & $2.5 \mathrm{a}$ & $3.2 \mathrm{a}$ & $4.3 \mathrm{a}^{*}$ & $4.9 \mathrm{a}$ \\
Bitter taste & $1.5 \mathrm{a}$ & $0.9 \mathrm{a}$ & $1.1 \mathrm{a}$ & $2.1 \mathrm{a}$ \\
Global appreciation & $4.7 \mathrm{a}$ & $5.3 \mathrm{a}$ & $6.5 \mathrm{a}^{*}$ & $5.5 \mathrm{a}$ \\
\hline
\end{tabular}

Values followed by different letters and asterisks are significantly different $(\mathrm{p}<0.05)$. Letters indicate differences between raw and pasteurized samples. Asterisks indicate differences among raw samples (RS1 vs RS2) and pasteurized samples (PS1 vs PS2)

Table 2 reports the results of biochemical analyses performed on tomato-based drinks. The two raw blends showed high contents of lycopene and polyphenols, as well as higher antioxidant activity. Interestingly, the heat treatment did not significantly alter the content of the above-mentioned functional compounds. In agreement with Giovannucci [9], we may hypothesize that the biochemical properties of S1 and S2 resulted quite stable after the thermal treatment because of the simultaneous presence of antioxidants (i.e. lycopene) and other micronutrients (i.e. minerals). These molecules can produce synergistic interactions able to preserve the functionality of polyphenols and carotenoids. As already reported by Dewanto et al. [26], also in this case, the lycopene content was increased after pasteurization (Table 2). This data is consistent with the ability of lycopene to increase its bio-accessibility following the thermal treatment [27]. Unlike sugar content decreased by $27.1 \%$ and $25.9 \%$ in S1 and S2, respectively. The sugar content decrease may be the result of chemical reactions (i.e. Mallard's reaction) induced by high pasteurization [25]. 
Table 2. Lycopene $\left(\mathrm{mg} \mathrm{L}^{-1}\right)$, antioxidant activity $\left(\mathrm{mg} \mathrm{L}^{-1}\right)$, total polyphenols $\left(\mathrm{mg} \mathrm{L}^{-1}\right)$, vitamin $\mathrm{C}\left(\mathrm{mg} \mathrm{L}^{-1}\right)$ and sugars $\left(\mathrm{kcal} \mathrm{L}{ }^{-1}\right.$ and $\left.\mathrm{g} \mathrm{L}{ }^{-1}\right)$ of tested combinations before (RS1, RS2) and after high pasteurization (PS1, PS2)

\begin{tabular}{|c|c|c|c|c|}
\hline \multirow{2}{*}{ Attributes } & \multicolumn{4}{|c|}{ Samples } \\
\hline & $\mathrm{RS} 1$ & PS1 & RS2 & PS2 \\
\hline Lycopene $\left(\mathrm{mg} \mathrm{L}^{-1}\right)$ & $188.9 \pm 1.8 b^{*}$ & $230.9 \pm 2.0 \mathrm{a}^{*}$ & $132.8 \pm 4.3 b$ & $149.6 \pm 3.1 \mathrm{a}$ \\
\hline Antioxidant activity, $\mathrm{AF}\left(\mathrm{mg} \mathrm{L}^{-1}\right)$ & $8229.4 \pm 680.6 a$ & $7813.7 \pm 849.9 \mathrm{a}$ & $8437.2 \pm 552.1 \mathrm{a}$ & $6705.2 \pm 611.9 \mathrm{~b}$ \\
\hline Antioxidant activity, $\mathrm{OF}\left(\mathrm{mg} \mathrm{L}^{-1}\right)$ & $762.0 \pm 106.7 \mathrm{a}$ & $730.2 \pm 114.2 \mathrm{a}$ & $1042.8 \pm 103.3 \mathrm{a}^{*}$ & $872.2 \pm 103.6 \mathrm{a}$ \\
\hline Total polyphenols $\left(\mathrm{mg} \mathrm{L}^{-1}\right)$ & $275.9 \pm 23.6 \mathrm{a}$ & $277.5 \pm 23.8 \mathrm{a}$ & $339.6 \pm 12.2 \mathrm{a}^{*}$ & $362.1 \pm 11.9 \mathrm{a}^{*}$ \\
\hline Vitamin $\mathrm{C}\left(\mathrm{mg} \mathrm{L}^{-1}\right)$ & $95.7 \pm 0.2 \mathrm{a}$ & $46.3 \pm 0.5 b$ & $105.5 \pm 0.8 \mathrm{a}^{*}$ & $100.4 \pm 0.4 b^{*}$ \\
\hline $\operatorname{Sugars}^{\mathrm{a}}\left(\mathrm{kcal} \mathrm{L}^{-1}\right)$ & $283.1 \pm 0.1 \mathrm{a}^{*}$ & $206.3 \pm 0.2 b^{*}$ & $272.8 \pm 0.2 \mathrm{a}$ & $202.16 \pm 0.1 b$ \\
\hline Sugars $\left(\mathrm{g} \mathrm{L}^{-1}\right)$ & $74.5 \pm 0.1 \mathrm{a}^{*}$ & $54.3 \pm 0.2 b^{*}$ & $71.8 \pm 0.2 \mathrm{a}$ & $53.2 \pm 0.1 b$ \\
\hline
\end{tabular}

Values followed by different letters and asterisks are significantly different $(\mathrm{p}<0.05)$. Letters indicate differences between raw and pasteurized samples. Asterisks indicate differences among raw samples (RS1 vs RS2) and pasteurized samples (PS1 vs PS2). All the analyses were made in triplicate. ${ }^{a}$ Kilocalories were calculated using the method described by Southgate and Durnin [28].

From a nutritional point of view, the two combinations provided satisfactory results. In fact, they showed a lower caloric intake (Table 2) compared with different energy drinks on the market (Table 3). These findings indicated that a drink based on fruit juices, including tomato juice, can be healthier than energy drinks, which are usually associated to a low nutritional value and a high caloric intake.

Table 3. Sugar content of different energy drinks used as comparison

\begin{tabular}{ccc}
\hline \multirow{2}{*}{ Energy drinks } & \multicolumn{2}{c}{ Sugar content $^{\mathrm{a}}$} \\
\cline { 2 - 3 } & Kcal L $^{-1}$ & $\mathrm{~g} \mathrm{~L}^{-1}$ \\
\hline Go\&Fun green & 414.2 & 109.0 \\
Red bull & 421.8 & 111.0 \\
Monster & 421.8 & 111.0 \\
\hline
\end{tabular}

${ }^{a}$ Data related to sugar content of reported energy drinks were collected on the market. Kilocalories were calculated using the method described by Southgate and Durnin (1970) [28].

The different volatile composition of S1 and S2 may explain their different sensory profiles (Table 4). In fact, RS2 showed a lower concentration of typical fresh tomato volatile compounds, such as 6-methyl-5-hepten-2-one, that is responsible for tomato-like flavour, or ethyl butanoate, hexanal and trans-2-hexenal, that are responsible for fresh-cut grass [29-33]. We may hypothesize that the lower amount of tomato volatile compounds associated to RS2 was mainly due to the major dilution of this blend, which has one more ingredient (orange juice) compared to RS1. The orange juice enriched the volatile composition of RS2 increasing the concentration of some esters [34]. These molecules contributed to mask the tomato odour, making the flavour more appetizing. In the same blends, new volatile compounds were found after high pasteurization. Most of these molecules (i.e. pentanal, trans-2-pentenal, nonanal, decanal, benzyl acetate, dimethylsulfide) were identified as being mainly responsible for sensory profile change of pasteurized drinks [35-37]. They contributed to make the tomato flavour more intense (higher perception of cooked tomato) and the taste more biting. 
Table 4. Volatile compounds ( $\mu \mathrm{g} \mathrm{L}^{-1}$ ) of the tested blends before (RS1, RS2) and after high pasteurization (PS1, PS2)

\begin{tabular}{|c|c|c|c|c|}
\hline Compound $\left(\mu \mathrm{g} \mathrm{L}^{-1}\right)$ & RS1 & PS1 & RS2 & PS2 \\
\hline Pentanal & ND & $9.8 \pm 3.9$ & ND & ND \\
\hline trans-2-Pentenal & ND & ND & ND & $14.4 \pm 1.0$ \\
\hline Hexanal & $1707.5 \pm 274.6 b$ & $1025.0 \pm 316.5 \mathrm{a}$ & $1174.9 \pm 213.1 \mathrm{a}$ & $904.6 \pm 243.2 \mathrm{a}$ \\
\hline Furfural & $12.5 \pm 0.7$ & ND & $41.7 \pm 3.3 * b$ & $21.7 \pm 3.8 \mathrm{a}$ \\
\hline trans-2-Hexenal & $460.1 \pm 90.7 \mathrm{a}$ & $753.7 \pm 206.2 \mathrm{a}$ & $436.5 \pm 117.3 b$ & $700.4 \pm 39.2 \mathrm{a}$ \\
\hline Heptanal & $27.7 \pm 2.4 * b$ & $2.8 \pm 1.6 \mathrm{a}$ & $17.9 \pm 4.9 \mathrm{a}$ & $18.2 \pm 3.9 \mathrm{a}$ \\
\hline Nonanal & ND & $36.1 \pm 5.8$ & ND & ND \\
\hline Decanal & ND & ND & ND & $3.1 \pm 0.5$ \\
\hline 2,4-Hexadienal $(\mathrm{E}, \mathrm{E})$ & $59.2 \pm 11.6 b$ & $26.0 \pm 9.3 \mathrm{a}$ & $64.8 \pm 2.4$ & ND \\
\hline cis-2-Heptenal & $109.2 \pm 9.6^{*} \mathrm{~b}$ & $68.7 \pm 11.0 \mathrm{a}$ & $83.8 \pm 4.8 b$ & $53.8 \pm 1.2 \mathrm{a}$ \\
\hline trans-2-octenal & ND & $13.0 \pm 3.5$ & $70.1 \pm 11.4 b$ & $35.3 \pm 1.7 \mathrm{a}$ \\
\hline 1-Penten-3-one & $51.8 \pm 1.8 \mathrm{a}$ & $58.6 \pm 31.2 \mathrm{a}$ & $91.7 \pm 10.5 * \mathrm{a}$ & $76.6 \pm 31.8 \mathrm{a}$ \\
\hline 6-Methyl-5-hepten-2-one & $135.9 \pm 29.2 \mathrm{a}$ & $198.8 \pm 42.4 \mathrm{a}$ & $97.1 \pm 30.9 \mathrm{a}$ & $151.1 \pm 2.8 \mathrm{a}$ \\
\hline Menthone (t) & $31.9 \pm 6.6 * \mathrm{a}$ & $45.2 \pm 7.8 \mathrm{a}$ & $19.9 \pm 1.8 \mathrm{a}$ & $28.0 \pm 6.3 \mathrm{a}$ \\
\hline Carvone (t) & $3.5 \pm 0.0$ & ND & $12.9 \pm 1.3 * \mathrm{a}$ & $11.3 \pm 1.5 \mathrm{a}$ \\
\hline trans-Geranylacetone (t) & $4.7 \pm 1.8 b$ & $9,9 \pm 0.7 \mathrm{a}$ & $9.6 \pm 2.0 * \mathrm{a}$ & $8.9 \pm 0.8 \mathrm{a}$ \\
\hline$\alpha$-Terpineol & $6.6 \pm 0.0 \mathrm{a}$ & $3.6 \pm 0.1 \mathrm{a}$ & $6.2 \pm 0.9 \mathrm{~b}$ & $24.6 \pm 2.9 \mathrm{a}$ \\
\hline Ethyl acetate & $43.0 \pm 7.3 \mathrm{a}$ & $39.8 \pm 17.2 \mathrm{a}$ & $25.5 \pm 10.6 \mathrm{a}$ & $34.0 \pm 3.7 \mathrm{a}$ \\
\hline Ethyl hexanoate & $102.1 \pm 11.8 * \mathrm{a}$ & $123.7 \pm 8.6 \mathrm{a}$ & $61.9 \pm 6.5 \mathrm{a}$ & $63.4 \pm 2.4 \mathrm{a}$ \\
\hline Isoamyl acetate & $27.8 \pm 4.0 * \mathrm{a}$ & $39.8 \pm 13.1 \mathrm{a}$ & $11.5 \pm 1.3 \mathrm{a}$ & $17.8 \pm 5.8 \mathrm{a}$ \\
\hline Ethyl butanoate & $253.5 \pm 2.0 * \mathrm{a}$ & $318.9 \pm 129.5 a$ & $155.1 \pm 56.8 \mathrm{a}$ & $186.7 \pm 12.0 \mathrm{a}$ \\
\hline cis-3-hexenyl acetate & $11.9 \pm 2.7 \mathrm{a}$ & $15.5 \pm 0.8 \mathrm{a}$ & $12.2 \pm 1.6 \mathrm{a}$ & $4.0 \pm 0.0 \mathrm{a}$ \\
\hline Benzyl acetate & ND & $5.3 \pm 1.8^{*}$ & ND & ND \\
\hline Isoamyl n-butyrate & $39.8 \pm 1.2$ & ND & ND & ND \\
\hline Linalool & $14.3 \pm 0.2 \mathrm{a}$ & $6.6 \pm 1.6 \mathrm{a}$ & $74.8 \pm 4.6 * b$ & $63.2 \pm 0.8 * a$ \\
\hline 2-Ethylfuran & $24.6 \pm 2.7 * b$ & $16.0 \pm 2.2 * \mathrm{a}$ & $14.2 \pm 4.5 \mathrm{a}$ & $14.7 \pm 0.9 \mathrm{a}$ \\
\hline 2-Methylfuran & ND & ND & $14.2 \pm 4.5 \mathrm{a}$ & $17.0 \pm 11.9 \mathrm{a}$ \\
\hline Limonene & $\operatorname{Tr}$ & $\operatorname{Tr}$ & $1549.0 \pm 543.6 \mathrm{a}$ & $1628.2 \pm 22.8 \mathrm{a}$ \\
\hline 2-Isobutylthiazole & $16.7 \pm 5.9 \mathrm{a}$ & $12.0 \pm 2.1 \mathrm{a}$ & $15.5 \pm 5.7 \mathrm{a}$ & $9.6 \pm 5.4 \mathrm{a}$ \\
\hline Dimethylsulfide (t) & ND & $15.2 \pm 5.3^{*}$ & ND & $17.3 \pm 5.9 *$ \\
\hline
\end{tabular}

Values followed by different letters and asterisks are significantly different $(\mathrm{p}<0.05)$. The asterisks indicate differences among raw samples $(\mathrm{RS} 1$ and RS2). Letters indicate differences between raw (RS1, RS2) and pasteurized (PS1, PS2) samples; ND = not detected; Tr = traces; (t) = The volatile compounds were tentatively identified.

Relationships between the sensory properties and chemical data related to S1 and S2 were established by PLS analysis (Figure 1). Global intensity and tomato flavour, which closely characterize RS1, were positively associated to sugar content and aromatic molecules typical of tomato (i.e. ethyl acetate, hexanal, heptanal, cis-2-heptenal). After the heat treatment, PS1 was positively correlated to sweet taste and esters as it should be a beverage based on red fruits. RS2 was positively associated with sour taste, red berry fruit flavour and aromatic molecules (i.e. esters and lactones). Unlike PS2 showed orange flavour and bitter taste more prominent. These attributes were positively correlated to total polyphenols, vitamin $\mathrm{C}$ content and antioxidant capacity. These data confirm our hypothesis that thermal treatment may stabilize the functional properties (total polyphenols and antioxidant activity) of tested beverages without significantly alter their sensory properties. 


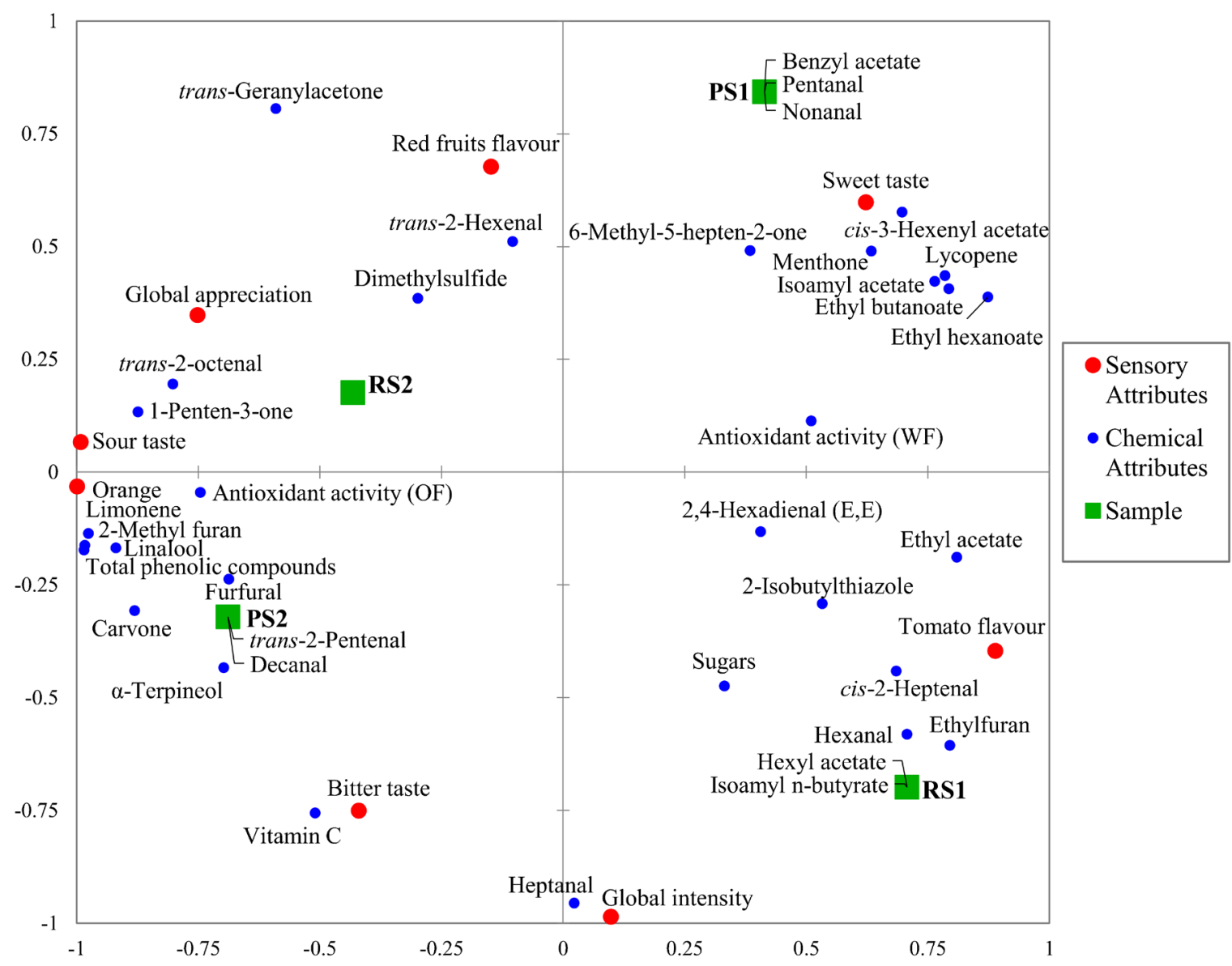

Figure 1. PLS analysis of tomato-based drinks performed on lycopene $\left(\mathrm{mg} \mathrm{L}^{-1}\right)$, total polyphenols $\left(\mathrm{mg} \mathrm{L}^{-1}\right)$, antioxidant activity $\left(\mathrm{mg} \mathrm{L}^{-1}\right)$, vitamin $\mathrm{C}\left(\mathrm{mg} \mathrm{L}^{-1}\right)$, sugars $\left(\mathrm{kcal} \mathrm{L}^{-1}\right)$, volatile compounds $\left(\mu \mathrm{g} \mathrm{L}^{-1}\right)$ and sensory data, before (RS1, RS2) and after high pasteurization (PS1, PS2)

\section{Conclusions}

In conclusion, the produced juice blends may likely to provide a better flavour as results of the simultaneous presence of aromatic compounds from different fruit sources, with nutritional and biochemical properties very similar to those of starting juices. Particularly, the two formulated tomato-based drinks showed sugar contents lower than those of different energy drinks on the market. S1 reported a suitable lycopene concentration, but the high tomato flavour can make this combination less appreciated. S2 showed high concentrations in total polyphenols and vitamin C. Interestingly, S2 was associated with a softer tomato flavour and high global appreciation. Moreover, high pasteurization $\left(90^{\circ} \mathrm{C}, 7 \mathrm{~min}\right)$ did not significantly affect sensory and biochemical properties of drinks.

These achievements might be useful to modulate tomato flavour release and consumer acceptability in the formulation of novel drinks based on tomato juice. Further studies are needed to confirm our findings and better understand how the industrial manufacturing process, as well as the storage conditions, can change the drink chemical composition and thus their sensory characteristics.

\section{References}

[1] Expert Market Research. Global Tomato Processing Market Report. Available from: https://www. expertmarketresearch.com/reports/tomato-processing-market/ [Accessed 16th September 2020].

[2] Tomato land. Trade and consumption. Available from: http://www.tomatoland.com/ [Accessed $16^{\text {th }}$ September 
2020].

[3] Research and Markets. Global Soft Drinks Market 2020-2024. Available from: https://www.researchandmarkets. com/reports/5135926/global-soft-drinks-market-2020-2024/ [Accessed 16th September 2020].

[4] Zenith Global Ltd. Soft drink reports. Available from: https://www.zenithglobal.com/ [Accessed 16th September 2020].

[5] Ehlers A, Marakis G, Lampen A and Hirsch-Ernst KI. Risk assessment of energy drinks with focus on cardiovascular parameters and energy drink consumption in Europe. Food and Chemical Toxicology. 2019; 130: 109-121. Available from: https://doi.org/10.1016/j.fct.2019.05.028/.

[6] Malinauskas BM, Aeby VG, Overton RF, Carpenter-Aeby T and Barber-Heidal K. A survey of energy drink consumption patterns among college students. Nutrition Journal. 2007; 6(35): 1-7. Available from: https://doi. org/10.1186/1475-2891-6-35/.

[7] Keaver L, Gilpin S, Fernandes da Silva J, Buckley C and Foley-Nolan C. Energy drinks available in Ireland: A description of caffeine and sugar content. Public Health Nutrition. 2017; 20(9): 1534-1539. Available from: https:// doi.org/10.1017/S1368980017000362/.

[8] Al-Shaar L, Vercammen K, Lu C, Richardson S, Tamez M and Mattei J. Health effects and public health concerns of energy drink consumption in the united states: A mini-review. Frontiers in Public Health. 2017; 5: 225. Available from: https://oi.org/10.3389/fpubh.2017.00225/.

[9] Giovannucci E. Tomatoes, tomato-based products, lycopene, and cancer: review of the epidemiologic literature. Journal of the National Cancer Institute. 1999; 91(4): 317-331. Available from: https://doi.org/10.1093/ jnci/91.4.317/.

[10] Krogh V, Freudenheim JL, D’Amicis A, Scaccini C, Sette S, Ferro-Luzzi A and Trevisan M. Food sources of nutrients of the diet of elderly Italians: II. Micronutrients. International Journal of Epidemiology. 1993; 22(5): 86977. Available from: https://doi.org/10.1093/ije/22.5.869/.

[11] Nursiwi A, Nurhartadi E, Utami R, Sari AM, Laksono PW and Aprilia EN. IOP conference series: Materials in: international conference on food science and engineering science and engineering. Characteristic of Fermented Whey Beverage with Addition of Tomato Juice (Lycopersicum esculentum). Bristol: IOP Publishing; 2017. p.012009.

[12] Zhu Y, Sims CA, Klee HJ and Sarnoski PJ. Sensory and flavor characteristics of tomato juice from garden gem and aroma tomatoes with comparison to commercial tomato juice. Journal of Food Science. 2018; 83(1): $153-161$. Available from: https://doi.org/10.1111/1750-3841.13980/.

[13] Zhu Y, Shen M, Sims CA, Marshall MR and House LA. Consumer preference and willingness to pay for tomato juice. International Food and Agribusiness Management Review. 2018; 21(1559-2448): 1167-1184. Available from: http://dx.doi.org/10.22004/ag.econ.284912/.

[14] Rabie MA, Soliman AZ, Diaconeasa ZS and Constantin B. Effect of pasteurization and shelf life on the physicochemical properties of physalis (physalis peruviana L.) Juice. Journal of Food Processing and Preservation. 2015; 39(6): 1051-1060. Available from: https://doi.org/10.1111/jfpp.12320/.

[15] Tandon KS, Baldwin EA, Scott JW and Shewfelt RL. Linking sensory descriptors to volatile and non-volatile components of fresh tomato flavor. Journal of Food Science. 2003; 68(7): 2366-2371. Available from: https://doi. org/10.1111/j.1365-2621.2003.tb05774.x/.

[16] Kim MK, Lee Y, Kwak HS and Kang M. Identification of sensory attributes that drive consumer liking of commercial orange juice products in Korea. Journal of Food Science. 2013; 78(9): S1451-S1458. Available from: https:// doi.org/10.1111/1750-3841.12227/.

[17] Vallverdú-Queralt A, Bendini A, Barbieri S, Di Lecce G, Martin-Belloso O and Toschi, TG. Volatile profile and sensory evaluation of tomato juices treated with pulsed electric fields. Journal of Agriculture and Food Chemistry. 2013; 61(8): 1977-1984. Available from: https://doi.org/10.1021/jf3051126/.

[18] Djuric Z, Powell LC. Antioxidant capacity of lycopene-containing foods. International Journal of Food Sciences and Nutrition. 2001; 52(2): 143-149. Available from: https://doi.org/10.1080/09637480020027000-4/.

[19] Singleton VL, Rossi JL. Colorimetry of total phenolics with phosphomolybdic-phosphotungstic acid reagents. American Journal of Enology and Viticulture. 1965; 16(3): 144-158. Available from: http://www.ajevonline.org/ content/16/3/144.full.pdf + html/.

[20] De Sio F, Servillo L, Loiuduce R and Castaldo D. A chromatographic procedure for the determination of carotenoids and chlorophylls in vegetable products. Acta Alimentaria. 2001; 30(4): 395-405. Available from: https://doi. org/10.1556/aalim.30.2001.4.8/.

[21] Re R, Pellegrini N, Proteggente A, Pannala A, Yang M and Rice-Evans C. Antioxidant activity applying an improved ABTS radical cation decolorization assay. Free Radical Biology and Medicine. 1999; 26(9): 1231-1237. Available from: https://doi.org/10.1016/S0891-5849(98)00315-3/. 
[22] Lees R. Food analysis: analytical and quality control methods for the food manufacturer and buyer. London: Leonard Hill Books; 1975.

[23] Lisanti MT, Piombino P, Genovese A, Pessina R and Moio L. Traditional Italian tomato (Lycopersicon esculentum Mill.) cultivars and their commercial homologues: differences in volatile composition. Italian Journal of Food Science. 2008; 3(20): 333-350.

[24] Serrano E, Beltrán J, Hernández F. Application of multiple headspace-solid-phase microextraction followed by gas chromatography-mass spectrometry to quantitative analysis of tomato aroma components. Journal of Chromatography $A$. 2009; 1216(1): 127-133. Available from: https://doi.org/10.1016/j.chroma.2008.11.026/.

[25] Martins SIFS, Jongen WMF, van Boekel MAJS. A review of Maillard reaction in food and implications to kinetic modelling. Trends in Food Science and Technology. 2000; 11(9-10): 364-373. Available from: https://doi. org/10.1016/S0924-2244(01)00022-X/.

[26] Dewanto V, Wu X, Adom KK and Liu RH. Thermal processing enhances the nutritional value of tomatoes by increasing total antioxidant activity. Journal of Agricultural Food Chemistry, 2002; 50(10): 3010-3014. Available from: https://doi.org/10.1021/jf0115589/.

[27] Colle I, Lemmens L, Van Buggenhout S, Van loey A and Hendrickx M. Effect of thermal processing on the degradation, isomerization, and bioaccessibility of lycopene in tomato pulp. Journal of Food Science. 2010; 75(9): C753-C759. Available from: https://oi.org/10.1111/j.1750-3841.2010.01862.x/.

[28] Southgate D and Durnin J. Calorie conversion factors. An experimental reassessment of the factors used in the calculation of the energy value of human diets. British Journal of Nutrition. 1970; 24(2): 517-535. Avallabile from: https://doi:10.1079/BJN19700050/.

[29] Berna AZ, Lammertyn J, Buysens S, Di Natale C and Nicolaï BM. Mapping consumer liking oftomatoes with fast aroma profiling techniques. Postharvest Biology and Technology. 2005; 38(2): 115-127. Available from: https://doi. org/10.1016/j.postharvbio.2005.05.013/.

[30] Azodanlou R, Darbellay C, Luisier JL, Villettaz JC and Amadò V. Development of a model for quality assessment of tomatoes and apricots. LWT-Food Science and Technology. 2003; 3682: 223-233. Available from: https://doi. org/10.1016/S0023-6438(02)00204-9/.

[31] Krumbein A, Peters P, Brückner B. Flavor compounds and a quantitative descriptive analysis of tomatoes (Lycopersicon esculentum Mill.) of different cultivars in short-term storage. Postharvest Biology and Technology. 2004; 32(1): 15-28. Available from: https://doi.org/10.1016/j.postharvbio.2003.10.004/.

[32] Abegaz EG, Tandon KS, Scott JW, Baldwin EA and Shewfelt, RL. Partitioning taste from aromatic flavor notes of fresh tomato (Lycopersicon esculentum, Mill) to develop predictive models as a function of volatile and non-volatile components. Postharvest Biology and Technology. 2004; 34(3): 227-235. Available from: https://doi. org/10.1016/j.postharvbio.2004.05.023/.

[33] Hayase F, Chung TY, Kato H. Changes of volatile components of tomato fruits during ripening. Food Chemistry. 1984; 14(2): 113-124. Available from: https://doi.org/10.1016/0308-8146(84)90050-5/.

[34] Moufida S, Marzouk B. Biochemical characterization of blood orange, sweet orange, lemon, bergamot and bitter orange. Phytochemistry. 2003; 62(8): 1283-1289. Available from: https://doi.org/10.1016/S0031-9422(02)00631$3 /$.

[35] Markovic K, Vahçic N, Kovaçevic Ganic K and Banovic, M. Aroma volatiles of tomatoes and tomato products evaluated by solid-phase microextraction. Flavour and Fragrance Journal. 2007; 22(5): 395-400. Available from: https://doi.org/10.1002/ffj.1811/.

[36] Van Boekel MAJS. Formation of flavor compounds in the Maillard reaction. Biotechnology Advances. 2006; 24(2): 230-233. Available from: https://doi.org/10.1016/j.biotechadv.2005.11.004/.

[37] Servili M, Selvaggini R, Taticchi A, Begliomini AL, and Montedoro G. Relationships between the volatile compounds evaluated by solid phase microextraction and the thermal treatment of tomato juice: optimization of the blanching parameters. Food Chemistry. 2000; 71(13): 407-415. Available from: https://doi.org/10.1016/S03088146(00)00187-4/. 